Tema: Solidificação/ Lingotamento

\title{
OTIMIZAÇÃO DOS PARÂMETROS DO LINGOTAMENTO CONTÍNUO NA MELHORIA DA QUALIDADE SUPERFICIAL DO TARUGO*
}

\author{
Hou Xuan ${ }^{1}$ \\ Paulo Carvalho Fernandes ${ }^{2}$ \\ Avanil Lucas da Silva ${ }^{3}$ \\ Ivan Luiz de Mattos Scripnic ${ }^{4}$
}

\begin{abstract}
Resumo
O objetivo deste trabalho foi estudar os parâmetros de lingotamento contínuo e os seus impactos na qualidade superficial do tarugo e principalmente relacionados às trincas superficiais. Alinhado com a literatura de solidificação do aço, a velocidade de lingotamento e a refrigeração secundária foram os parâmetros focados no trabalho devido a sua forte influencia na geração e propagação das trincas superficiais do tarugo. Os parâmetros de processo foram comparados com os utilizados nas outras usinas de aços especiais que são benchmarking em qualidade superficial e as boas práticas aplicadas no equipamento da Gerdau Pindamonhangaba. O resultado deste trabalho gerou uma redução de $40 \%$ no sucatamento por trincas superficiais em barras laminadas.
\end{abstract}

Palavra-chave: Lingotamento contínuo; Trincas superficiais; Velocidade de lingotamento; Refrigeração secundária.

\section{OTIMIZATION OF CONTINUOUS CASTER PARAMETERS TO IMPROVE SURFACE QUALITY OF THE BILLET}

\begin{abstract}
This work has the objective of study the impact of continuous casting parameters on billets surface defects, mainly related to surface cracks. Aligned with the steel solidification literature, casting speed and secondary cooling were the parameters focused on this work due to their strong influence on generation and propagation of surface cracks on the billet. The process parameters were compared with others specialty steel mills that have benchmark practices in term of surface quality of the billet. These good practices were then applied on the Gerdau Pindamonhangaba equipment. The result of this work has reduced the surface quality defect on rolled bars in $40 \%$.
\end{abstract}

Key words: Continuous casting; Surface cracks; Casting speed; Secondary cooling.

1 Engenheiro Químico, Assessor Técnico de Aciaria, Gerdau Pindamonhangaba, Pindamonhangaba, SP, Brasil.

2 Engenheiro Metalurgista, Consultor Técnico de Aciaria, Gerdau Aços Especiais Brasil, Porto Alegre, RS, Brasil.

3 Engenheiro de Produção Mecânica, Chefe do Lingotamento Contínuo, Gerdau Pindamonhangaba, Pindamonhangaba, SP, Brasil.

4 Engenheiro Metalurgista, Gerente da Aciaria, Gerdau Pindamonhangaba, Pindamonhangaba, SP, Brasil.

* Contribuição técnica ao $45^{\circ}$ Seminário de Aciaria - Internacional, 25 a 28 de maio de 2014, 


\section{INTRODUÇÃO}

\subsection{Gerdau Aços Especiais Brasil - Unidade Pindamonhangaba}

A Gerdau Pindamonhangaba pertence a unidade de negócio Aços Especiais Brasil do Grupo Gerdau. A Aciaria desta unidade tem capacidade de produção de 600 mil t/ano de tarugos destinados principalmente ao mercado automobilístico. O processo metalúrgico é realizado em forno elétrico a arco, forno panela, desgaseificador, lingotamento contínuo ou lingotamento convencional.

Os aços destinados a aplicação na indústria automotiva possuem exigências de qualidade bastante criteriosas de acordo com as normas de qualidade estabelecidas pelos clientes. Dentre estas exigências estão requisitos de qualidade relacionados à isenção de defeitos tanto internos quanto superficiais. A qualidade superficial das barras laminadas proveniente dos tarugos do Lingotamento Contínuo é caracterizada pela presença ou isenção de defeitos superficiais. Em se tratando de produtos destinados a aplicação na indústria automotiva, este é um requisito fundamental para garantir a qualidade e a vida útil de componentes mecânicos.

Trincas superficiais em tarugos produzidas no Lingotamento Contínuo são fissuras que ocorrem na superfície dos tarugos durante o processo de lingotamento. As consequências advindas desses defeitos vão deste a necessidade de inspeção do tarugo para posterior remoção das trincas, até o sucatamento do produto intermediário ou final, devido à impossibilidade da remoção dos defeitos. Esta impossibilidade pode estar associada ao grande número de trincas presentes no produto e/ou a profundidade destas ser acima da tolerância admitida pelo cliente. Uma alternativa para evitar o sucatamento está no torneamento das barras laminadas para uma bitola menor, o que necessariamente, envolve uma perda de material (baixo rendimento do processo), ocupação das máquinas em operações de retrabalho, aumento do tempo de fabricação e atraso no atendimento ao cliente. $\mathrm{Na}$ Figura 1 é apresentado exemplo de trinca superficial encontrada em uma barra laminada e sua análise metalográfica.

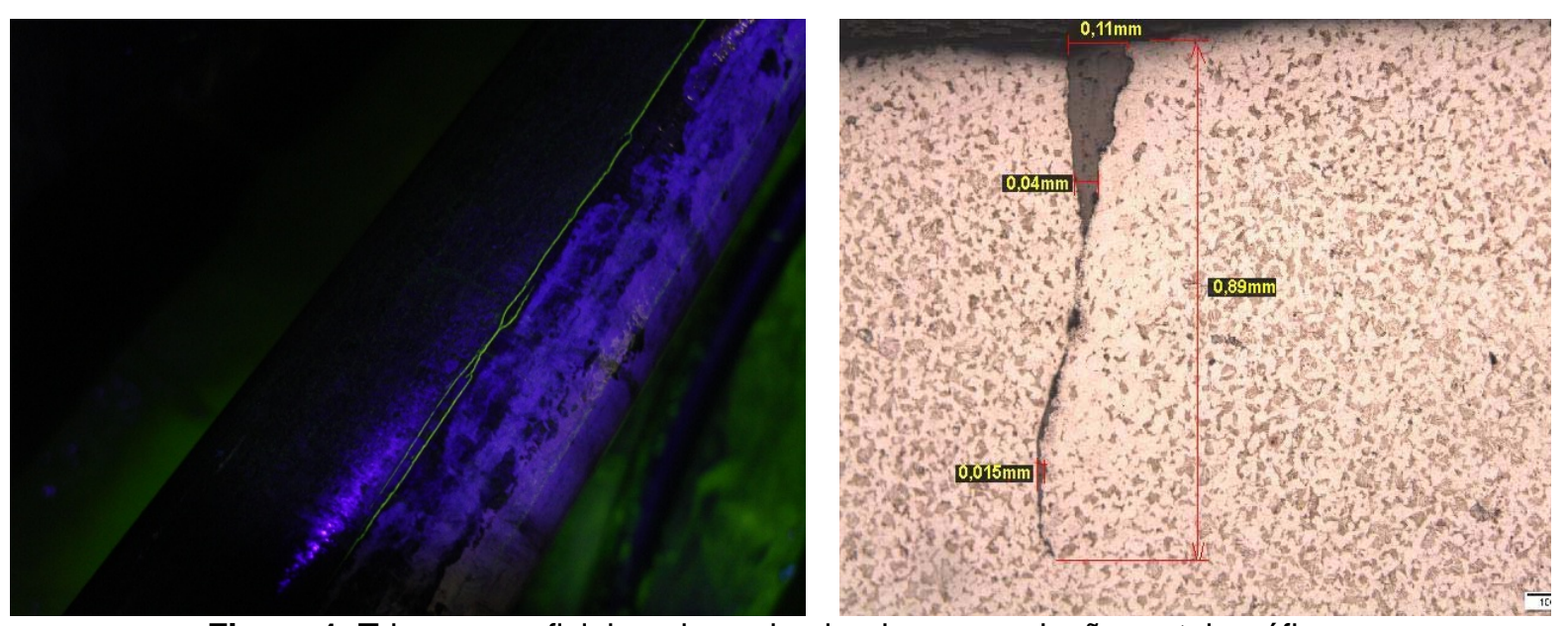

Figura 1. Trinca superficial em barra laminada e a revelação metalográfica.

\subsection{Defeitos Superficiais}

Os principais defeitos superficiais e internos em tarugo de lingotamento contínuo são mostrados na Figura 2. Os defeitos que serão focados neste trabalho são as trincas superficiais.

* Contribuição técnica ao 45 Seminário de Aciaria - Internacional, 25 a 28 de maio de 2014, Porto Alegre, RS, Brasil. 

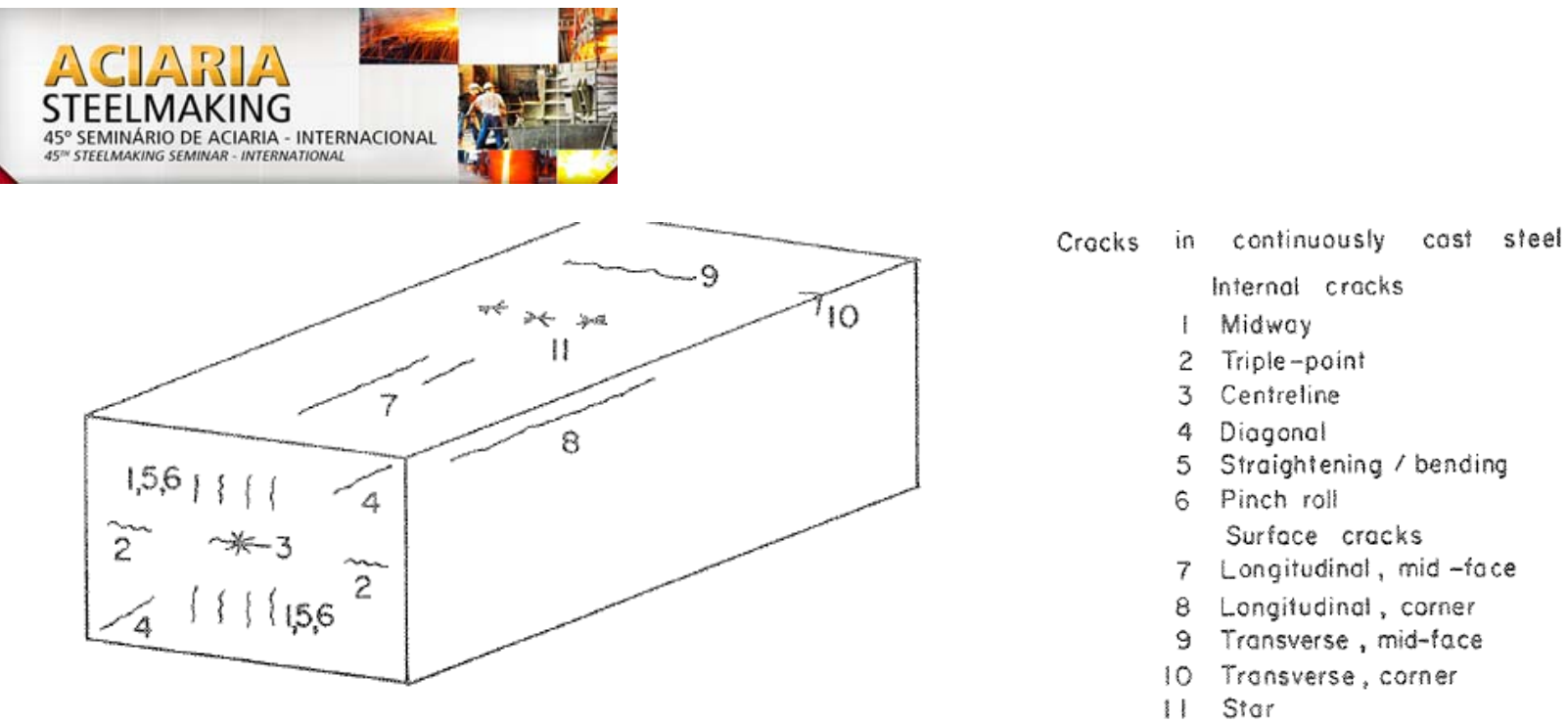

Figura 2. Defeitos típicos em lingotamento contínuo [1].

Para entender como as trincas superficiais surgem, deve-se entender o conceito de faixas de fragilidade em função da temperatura. De acordo com Suzuki [2] existem três intervalos de temperaturas frágeis (Brittle Temperatures Ranges - BTR). Na Figura 3 estão apresentadas as três faixas de fragilidade em função da temperatura.

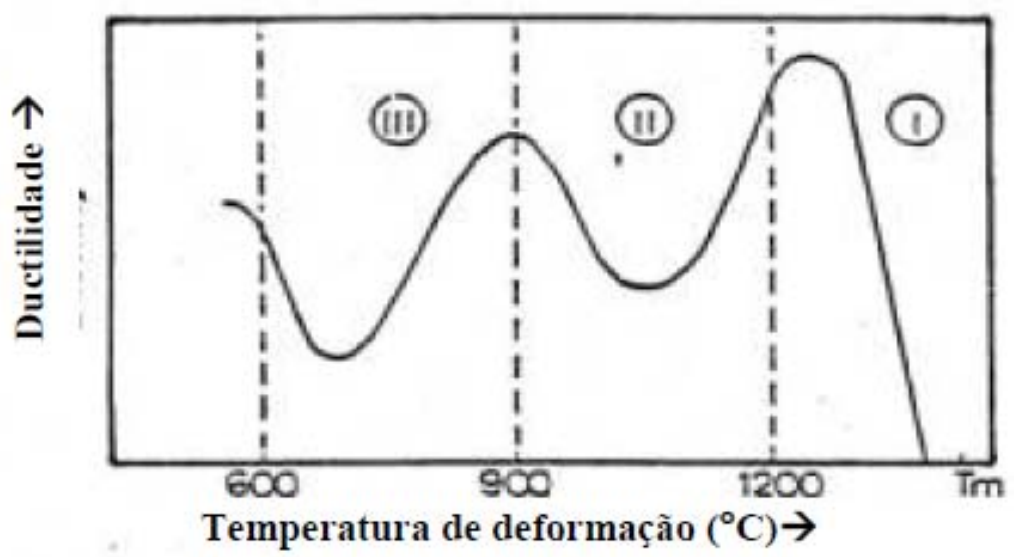

Figura 3. Faixas de fragilidade em função da temperatura [2].

As estruturas existentes com os seus precipitados característicos para cada intervalo de fragilidade podem ser observadas na Figura 4. Na zona I vê-se a frente de solidificação mostrando as dendritas e as trincas entre as frentes de crescimento de dendritas. Na zona II é mostrada a presença de óxidos/sulfetos de manganês ou ferro nos contornos de grão austeníticos como também a possibilidade de surgimento de carepa rica em $\mathrm{Cu}$, $\mathrm{Sn}$ e $\mathrm{Sb}$, debilitando a coesão do contorno de grão na região superficial. Já na zona III é mostrada a ocorrência de precipitados AIN, BN e $\mathrm{Nb}(\mathrm{C}, \mathrm{N})$ nos contornos de grão austeníticos.

* Contribuição técnica ao 450 Seminário de Aciaria - Internacional, 25 a 28 de maio de 2014, Porto Alegre, RS, Brasil. 

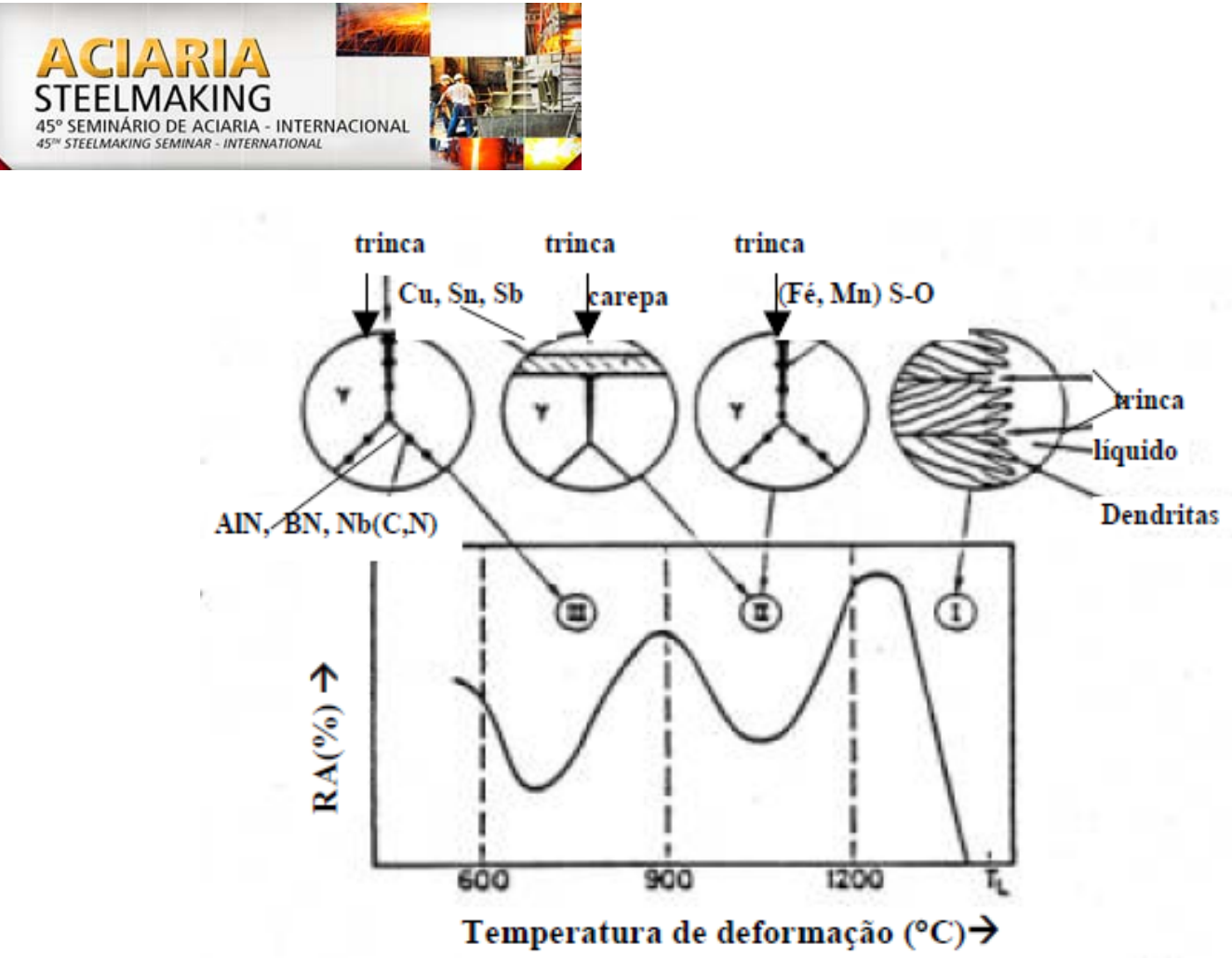

Figura 4. Estruturas e precipitados de cada intervalo de fragilidade [2].

A Figura 5 mostra além das estruturas da figura 4, veios de ferrita entre os grãos de austenita ou perlita. Dentro da ferrita depositam-se os precipitados de AIN, BN, Nb $(\mathrm{C}, \mathrm{N})$.

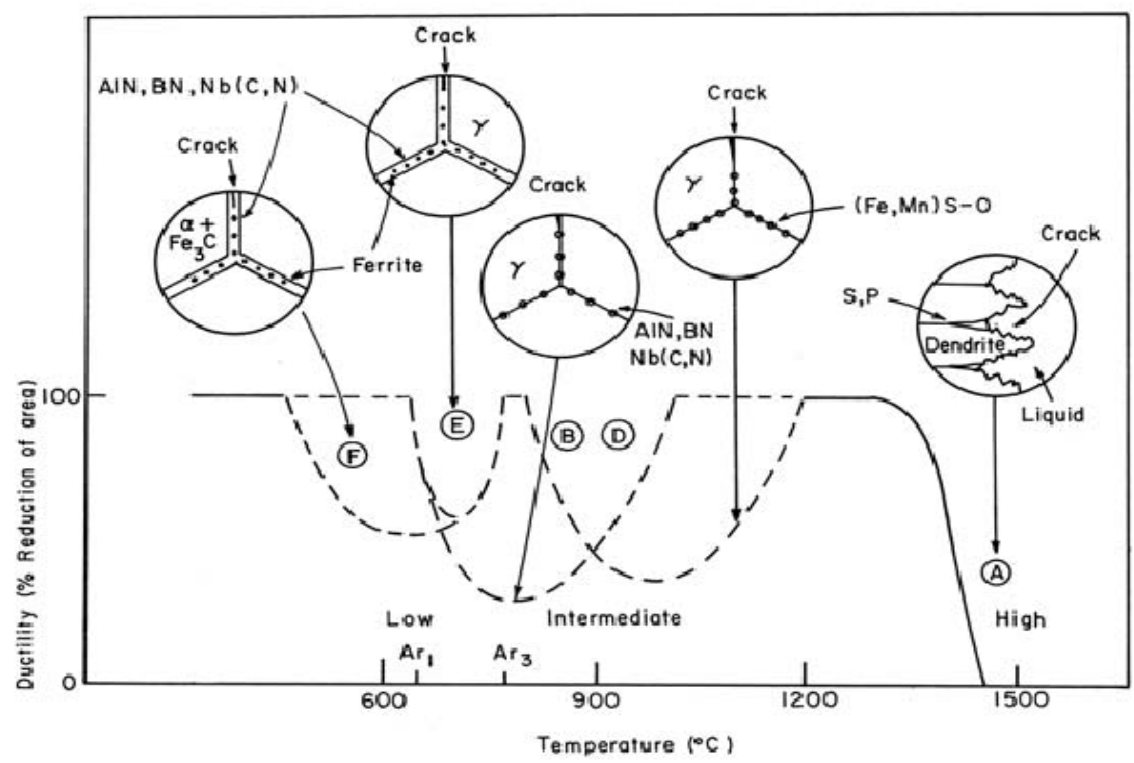

Figura 5. Estruturas e precipitados de cada intervalo de fragilidade [2].

A caracterização resultante da Figura 5 é apresentada na tabela 1 e indica que as trincas superficiais, apesar de sua correspondência com os distintos intervalos BTRs, também têm relação com a morfologia da microestrutura de solidificação primária.

* Contribuição técnica ao $45^{\circ}$ Seminário de Aciaria - Internacional, 25 a 28 de maio de 2014, Porto Alegre, RS, Brasil. 
Tabela 1. Trincas Superficiais versus o intervalo de temperaturas frágeis, BTR, como uma função da morfologia da microestrutura [1]

\begin{tabular}{|c|c|c|c|c|}
\hline Tipo de Trinca & Microestrutura & \multicolumn{3}{|c|}{ Intervalo de Temperatura Frágil } \\
\hline Logitudinal de canto & $\begin{array}{l}\text { Dendrítica } \\
\text { Colunar }\end{array}$ & $\mathrm{I}$ & & \\
\hline $\begin{array}{l}\text { Subsuperficial } \\
\text { próxima ao canto }\end{array}$ & $\begin{array}{l}\text { Dendrítica } \\
\text { Colunar }\end{array}$ & I & & \\
\hline $\begin{array}{l}\text { Ruptura/Agarramento } \\
\text { Transversal }\end{array}$ & $\begin{array}{l}\text { Dendrítica } \\
\text { Colunar }\end{array}$ & I & & \\
\hline Em rede (estrela) & $\begin{array}{l}\text { Grão } \\
\text { Austenítico } \\
\text { Grosseiro } \\
\end{array}$ & & & III \\
\hline Longitudinal de Face & $\begin{array}{l}\text { Grão } \\
\text { Austenítico } \\
\text { Grosseiro }\end{array}$ & (I) & II & \\
\hline $\begin{array}{l}\text { Face/transversal de } \\
\text { canto }\end{array}$ & $\begin{array}{l}\text { Grão } \\
\text { Austenítico } \\
\text { Grosseiro }\end{array}$ & (I) & II & III \\
\hline
\end{tabular}

De acordo com esta tabela pode-se fazer as seguintes observações:

- Trincas em BTR I são relacionadas fundamentalmente com a estrutura dendrítica colunar primária. Estas trincas usualmente estão preenchidas por um aço líquido rico em soluto (segregação ou ghost lines), assim, são denominadas trincas intercolunares. Uma estrutura equiaxial raramente apresenta uma descoesão interdendrítica (Figura 4).

- Trincas em BTR II e III são comumente relacionadas a grãos de austenita grosseiros, devido a profundas marcas de oscilação e depressões superficiais fortes no veio, as quais reduzem a taxa de resfriamento local. (Figura 5).

\section{MATERIAL E MÉTODOS}

Os principais parâmetros de processo do lingotamento contínuo estudado neste trabalho foram: velocidade de lingotamento e a refrigeração secundária. Os valores de velocidade lingotamento por qualidade de aço e os parâmetros da refrigeração secundária foram comparados com os valores praticados nas melhores usinas de aços especiais da Gerdau no mundo em termos de sucatamento por trinca superficial. O projeto e condição dos equipamentos, as restrições e as particularidades foram levantados e comparados.

\subsection{Velocidade de Lingotamento}

A velocidade de lingotamento influencia fortemente na temperatura do tarugo durante o endireitamento do mesmo, afetando assim, a propriedade de ductilidade a quente do material, dessa forma impacta na geração ou propagação de trincas no intervalo de temperatura frágil III (BTR III) causadas por tensão mecânica (tração) na superfície do tarugo [1]. Quanto maior a velocidade de lingotamento maior a temperatura do tarugo no endireitamento e menor a formação ou propagação das trincas superficiais. Comparando as velocidades praticadas na Gerdau Pindamonhangaba com as outras usinas de aços especiais, elas estão em média

* Contribuição técnica ao 45 Seminário de Aciaria - Internacional, 25 a 28 de maio de 2014, 


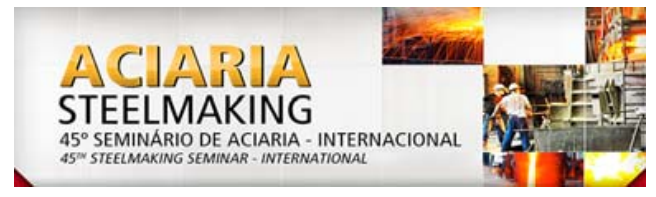

$20 \%$ a $35 \%$ mais baixas. Além disso, o aumento da velocidade aumenta a taxa de deformação do tarugo que por sua vez evita que os microvazios existentes no contorno de grão coalescem durante o processo da deformação e evoluam para trinca superficial [1]. Para aumentar a velocidade de lingotamento algumas melhorias foram estudadas e implantadas.

\subsubsection{Molde parabólico}

O molde utilizado na Gerdau Pindamonhangaba tinha o perfil do "taper" linear e não favorecia a extração do calor principalmente para os aços peritéticos que sofrem uma alta contração no decorrer da solidificação [1]. Aumentando a velocidade de lingotamento nestas condições, aumenta-se o risco de perfuração da casca solidificada na saída do molde. A melhoria implantada em relação ao molde foi a instalação dos moldes com perfil do "taper" parabólico, que acompanha melhor a contração da casca solida no decorrer da solidificação e permite uma extração de calor mais eficiente. A Figura 6 mostra uma ilustração do perfil de extração de calor entre o molde linear e parabólico, onde se verifica que o perfil do parabólico é maior que o do molde linear.
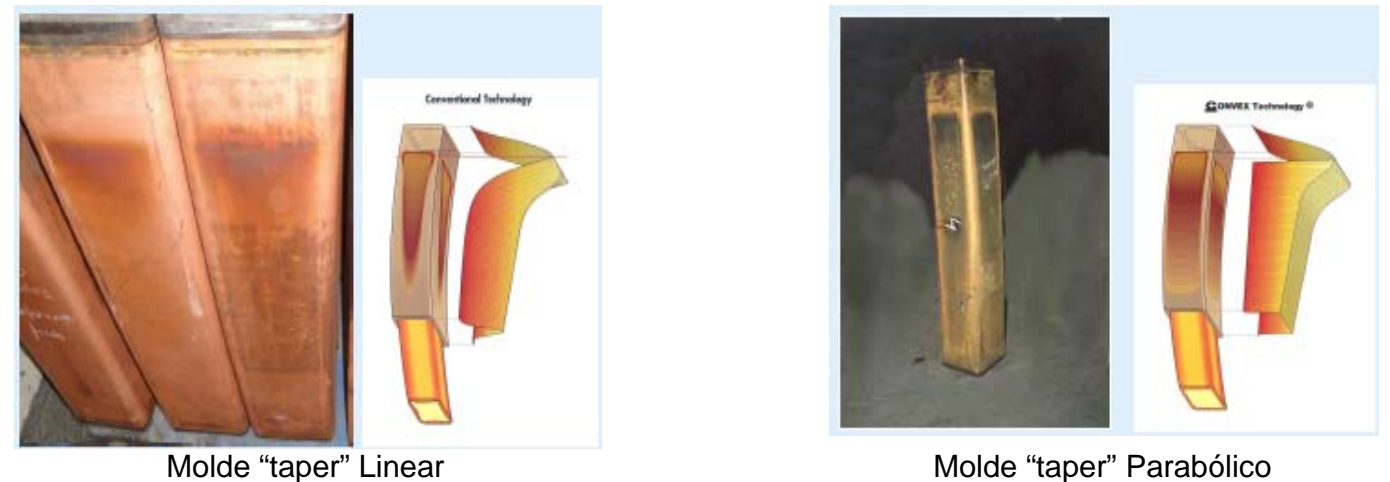

Figura 6. Ilustração do perfil de extração de calor do molde linear e molde parabólico.

\subsubsection{Rolo de pé}

A segunda condição para aumento da velocidade de lingotamento foi a instalação do conjunto rolo de pé entre os sprays do anel da refrigeração secundária. O aumento da velocidade reduz o tempo de residência do aço dentro do molde $e$ conseqüentemente reduz a espessura da casca formada na refrigeração primária. Dessa forma, na saída do molde, essa pele solidificada pode não suportar a pressão ferrostática exercida pelo aço liquido no interior do tarugo e causar um rompimento da pele. O conjunto de rolo de pé tem função de exercer uma contenção mecânica na pele solidificada na saída do molde e reduzir a chance de ocorrer uma perfuração. A Figura 7 ilustra a localização da instalação do conjunto rolo de pé na saída do molde.

* Contribuição técnica ao $45^{\circ}$ Seminário de Aciaria - Internacional, 25 a 28 de maio de 2014, 

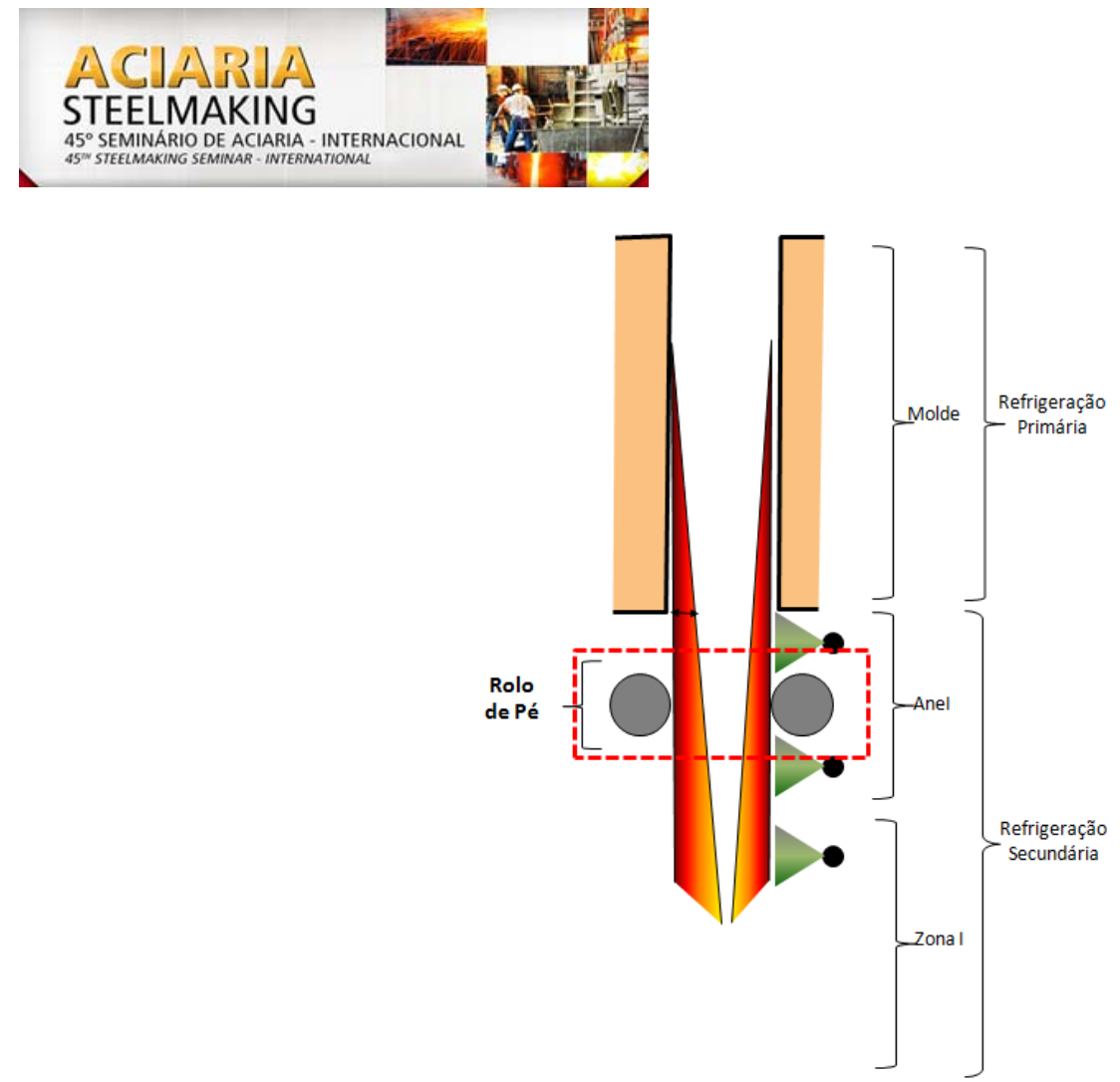

Figura 7. Ilustração do posicionamento do conjunto rolo de pé.

\subsection{Refrigeração Secundária}

A refrigeração secundária tem forte influência na geração das trincas superficiais [1]. O resfriamento excessivo reduz muito a temperatura da casca solidificada, que na saída da zona de sprays, esta casca é reaquecida pelo aço liquido do seu interior, gerando uma tensão térmica na região e dependendo da fragilidade do material, pode gerar trincas de tensão térmica. Além disso, excesso de refrigeração secundária também reduz a temperatura do tarugo no endireitamento e gera trincas superficiais por tensão mecânica (tração). Comparando a quantidade de água injetada na refrigeração secundária na Gerdau Pindamonhangaba com as outras usinas de aços especiais, a quantidade específica estava entre $40 \%$ a $60 \%$ superior. No entanto para redução da água de refrigeração algumas melhorias foram necessárias.

\subsubsection{Modificação do projeto da câmara de spray}

$\mathrm{Na}$ avaliação do projeto da câmara de spray verificou-se que este não era adequado para uma refrigeração uniforme do tarugo. A distância dos bicos para as faces do tarugo era grande, pois o projeto original havia sido desenvolvido tanto para a seção de $155 \mathrm{~mm}$ quanto para a seção de $185 \mathrm{~mm}$, porém atualmente apenas a seção de $155 \mathrm{~mm}$ é produzida nesta unidade. Existem interferências entre os cones de spray prejudicando o desempenho dos mesmos, além disso, como o projeto de refrigeração atendia ambas as seções, no tarugo $155 \mathrm{~mm}$ havia um super resfriamento dos cantos com o "overspraying" dos sprays. A Figura 8 mostra o projeto da refrigeração secundária e a Figura 9 mostra as alterações realizadas na eliminação das interferências e super resfriamento dos cantos.

* Contribuição técnica ao $45^{\circ}$ Seminário de Aciaria - Internacional, 25 a 28 de maio de 2014, 

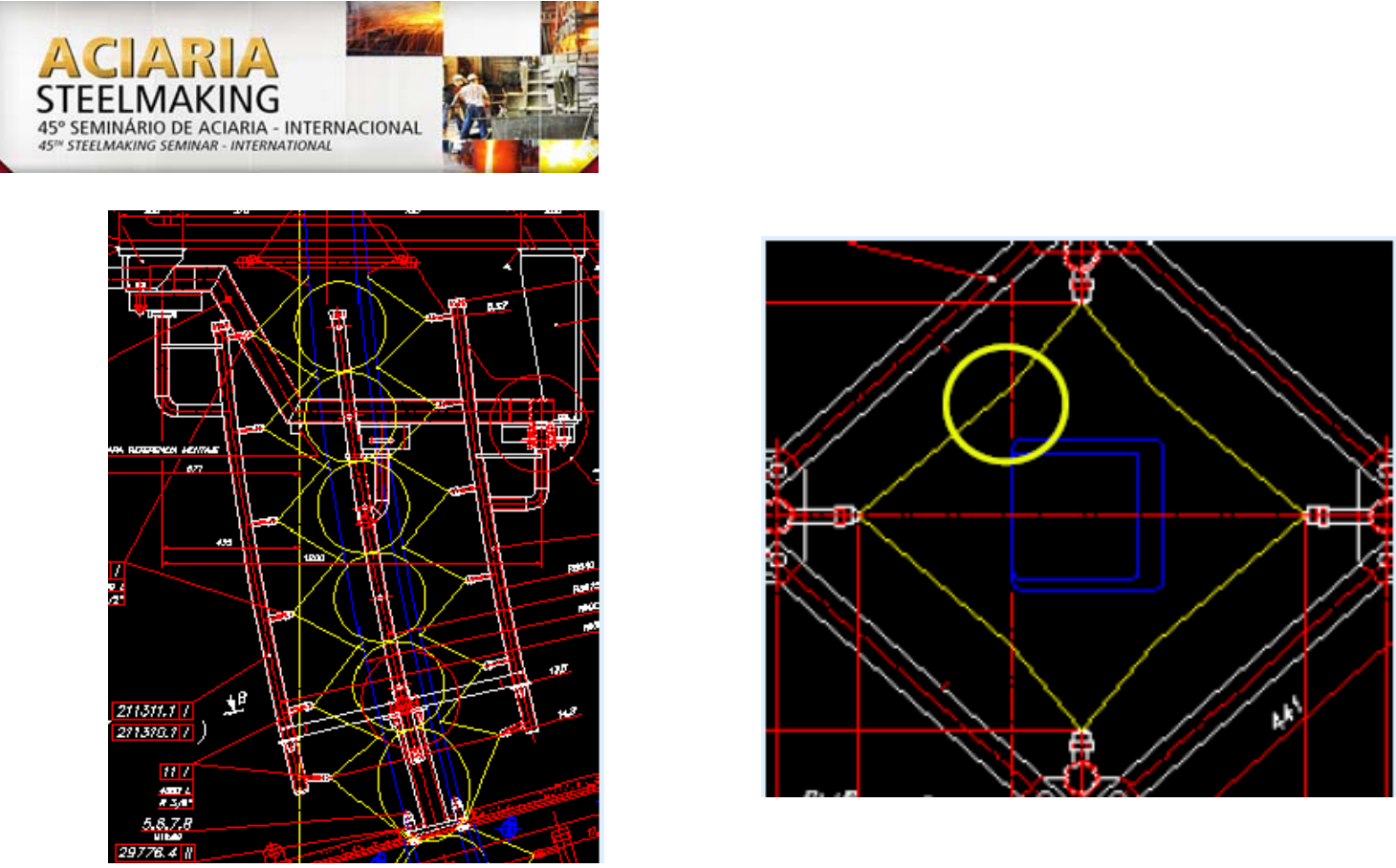

Figura 8. Projeto antigo da refrigeração secundária com interferência dos cones de spray.
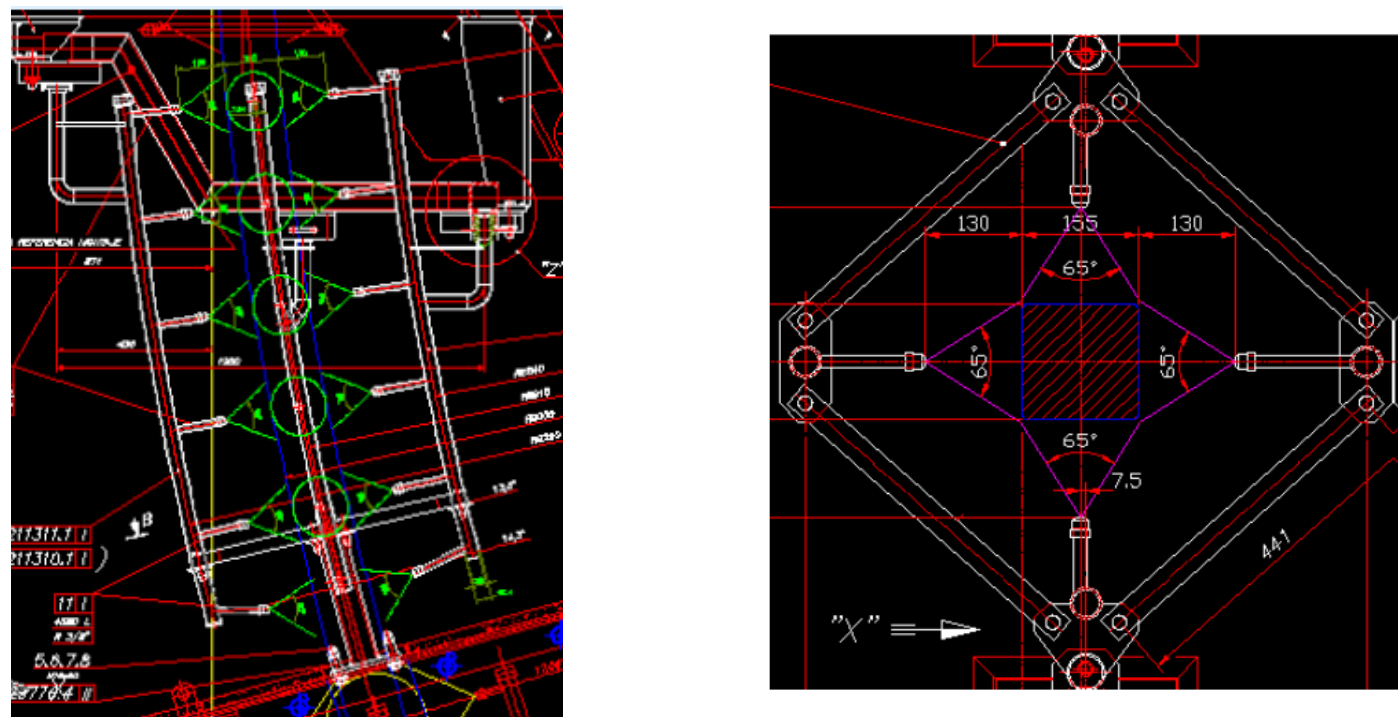

Figura 9. Novo projeto com eliminação das interferências dos cones de spray.

\subsubsection{Modificação do design dos bicos de sprays}

Com o objetivo de reduzir a quantidade especifica de água na refrigeração secundária o design dos bicos de spray também foi modificado. No design antigo, os orifícios dos bicos eram grandes e ocorria instabilidade da pressão quando se operava com baixas vazões, afetando o desempenho dos mesmos. Os bicos foram modificados para que, em baixas vazões, eles estejam operando com pressões superiores a 1,5 bar e tenham melhor estabilidade.

Além disso, o novo design dos bicos possui seis aberturas de entrada de água enquanto o antigo possui somente duas. Quando ocorria entupimento em uma destas aberturas por solido suspenso, no antigo design o cone do spray era desestabilizado, porém no novo design se uma abertura sofrer o entupimento, o perfil do cone de spray ainda estaria bom. Na Figura 10 mostra as diferenças das aberturas de entrada de água dos bicos.

\footnotetext{
* Contribuição técnica ao 45 Seminário de Aciaria - Internacional, 25 a 28 de maio de 2014,
} 

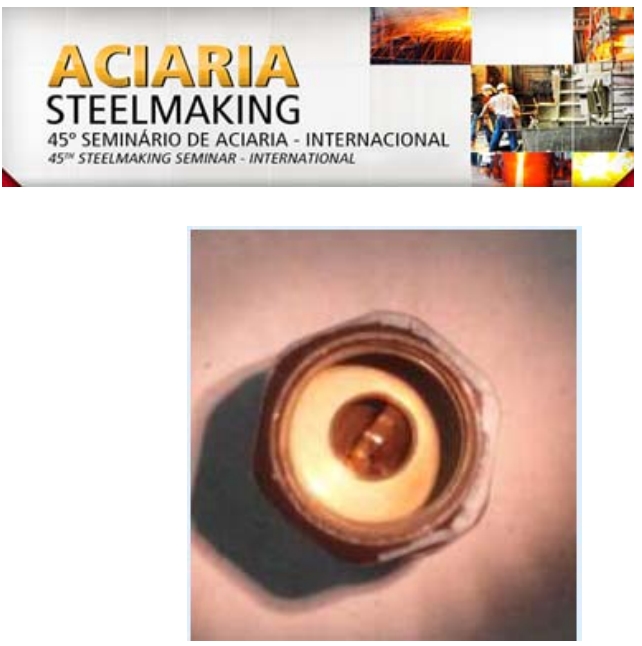

Design antigo

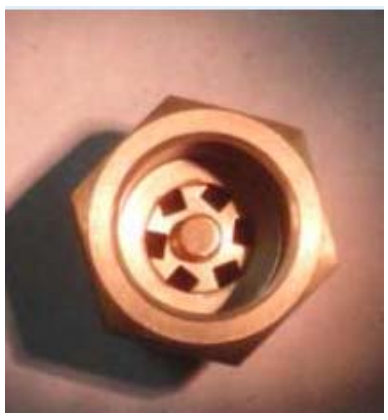

Novo design

Figura 10. Aberturas das entradas de água dos bicos de spray.

\section{RESULTADO E DISCUSSÕES}

\subsection{Aumento da Velocidade de Lingotamento}

Com a implantação do molde parabólico e rolos de pé, foi realizado um teste operacional em um veio do lingotamento contínuo com aumento da velocidade de lingotamento em 25\%. A Figura 11 mostra dois gráficos do teste com a velocidade mais alta $A$ em relação $B$ e por consequência o aumento da temperatura em até $100^{\circ} \mathrm{C}$ na face do tarugo no endireitamento melhorando assim a propriedade de ductilidade a quente do material.

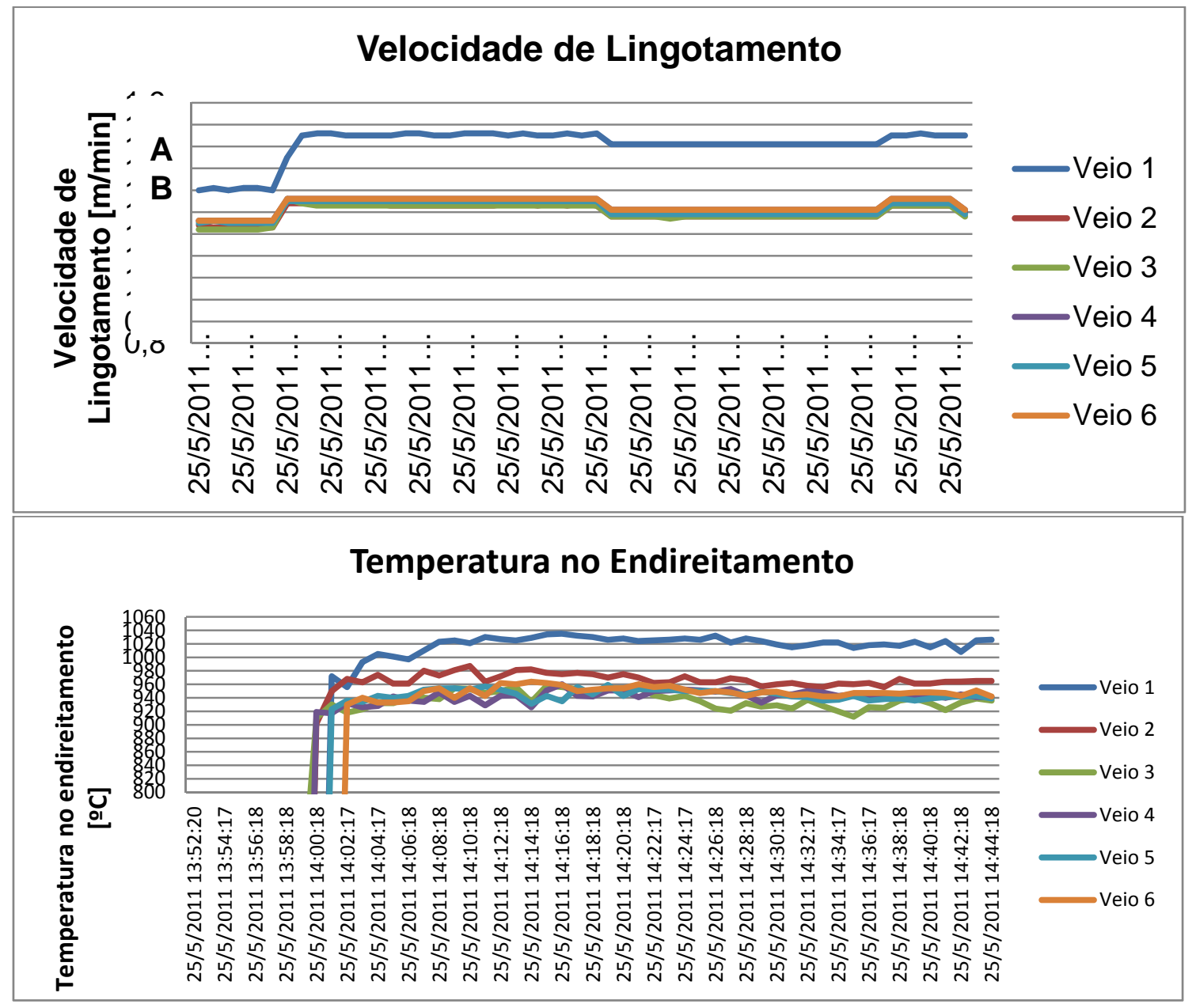

Figura 11. Aumento da velocidade de lingotamento em $25 \%$ e a temperatura no endireitamento.

* Contribuição técnica ao 450 Seminário de Aciaria - Internacional, 25 a 28 de maio de 2014, 


\subsection{Redução da Água de Refrigeração}

Após a implantação da nova refrigeração secundária e a troca dos bicos de spray, um teste operacional foi realizado em um veio do lingotamento contínuo com redução de $50 \%$ na injeção de água. Na Figura 12 mostra os tarugos na saída da câmara de spray onde no veio com a refrigeração padrão apresenta manchas escuras de resfriamento excessivo ao longo do tarugo e no veio teste com refrigeração reduzida observa-se a eliminação destas manchas escuras.

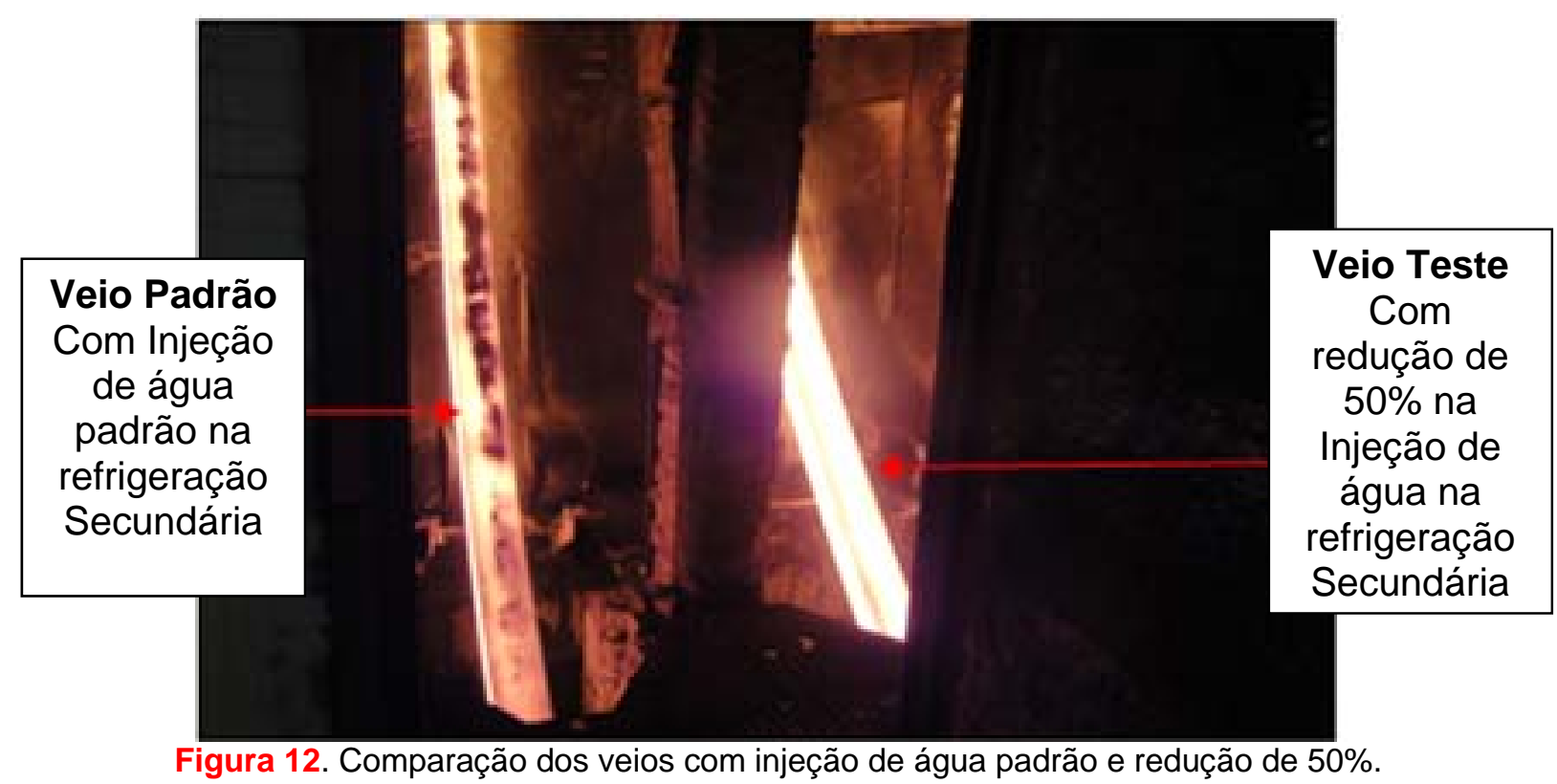

A Figura 13 é o indicador interno de acompanhamento dos índices de sucatamento por trincas superficiais em barras laminadas inspecionadas nas linhas automáticas de inspeção. O numerador é a quantidade total de sucata [t] por trincas superficiais de todas as qualidades que passam pela linha de inspeção e o denominador é a quantidade total de barras inspecionadas [t]. Verifica-se que após a padronização do aumento da velocidade de lingotamento e a redução da água da refrigeração secundária no final de 2011, o índice de sucatamento médio caiu em torno de $40 \%$ e o processo passou a ser muito mais estável.

* Contribuição técnica ao 450 Seminário de Aciaria - Internacional, 25 a 28 de maio de 2014, Porto Alegre, RS, Brasil. 

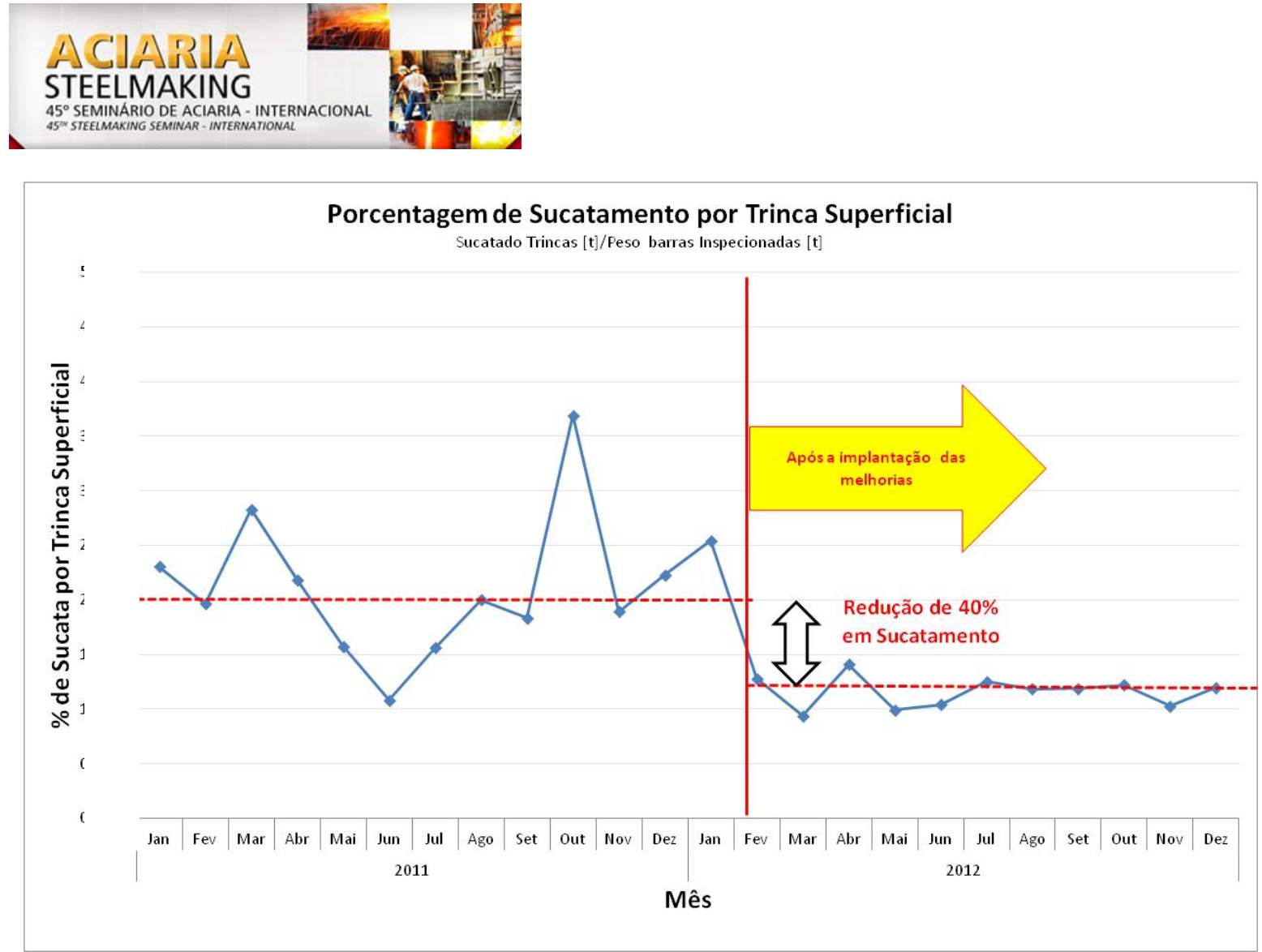

Figura 13. Indicador de sucatamento por trincas superficiais.

\section{CONCLUSÕES}

O resultado mostrou que os parâmetros do lingotamento contínuo focado neste trabalho trouxeram excelentes resultados em termos de redução dos defeitos superficiais de origem da Aciaria em barras laminadas. Alinhados com a literatura e os parâmetros praticados em outras usinas de aços especiais da Gerdau conseguiuse chegar a níveis de sucatamento próximos aos valores das usinas benchmarks da Gerdau. Além disso, o resultado deste trabalho também gerou ganhos importantes em redução de retrabalho nas áreas de acabamento/inspeção e principalmente produtos com níveis qualidade entre as melhores usinas de aços especiais da Gerdau.

\section{Agradecimentos}

Os autores agradecem a Gerdau Aços Especiais Brasil pela liberação da divulgação deste trabalho. Agradecem pelo empenho, dedicação dos colaboradores do Lingotamento Contínuo e o apoio de todos os colaboradores da Aciaria, Acabamento, PCP, Qualidade e TAE da usina de Pindamonhangaba que contribuíram fortemente para o sucesso dos resultados.

\section{REFERÊNCIAS}

1 Fernandes PC. Otimização dos parâmetros do lingotamento contínuo para minimizar a ocorrência de trincas superficiais no aço DIN20MnCr5Mod [dissertação de mestrado]. Porto Alegre: Escola de Engenharia, UFRGS; 2005.

2 Suzuki HG, Nishimura S, Yamaguchi S. Characteristics of hot ductility in steels subjected to the melting and solidification. Transactions ISIJ. 1982;22:48-56.

* Contribuição técnica ao $45^{\circ}$ Seminário de Aciaria - Internacional, 25 a 28 de maio de 2014, Porto Alegre, RS, Brasil. 